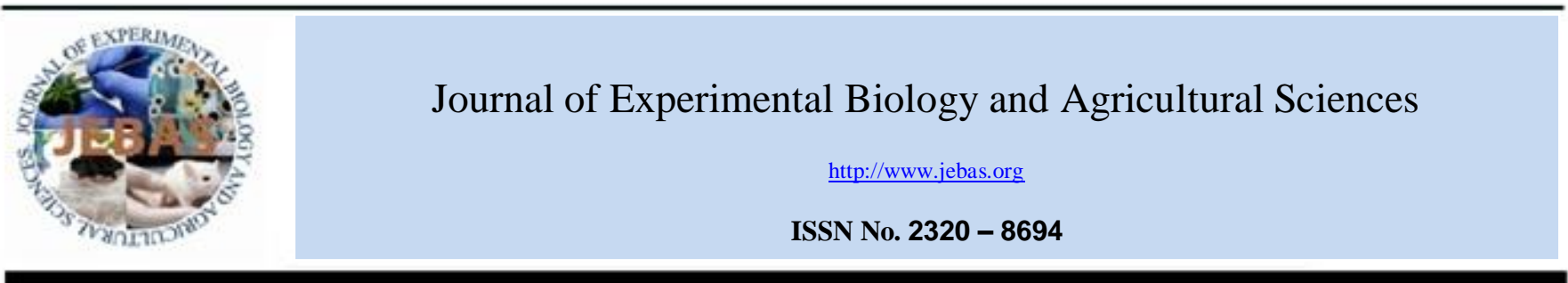

\title{
PNEUMATIC SEPARATION OF MAMI CULTIVAR ALMOND (Prunus amygdalus) KERNEL FROM CRACKED SHELL
}

\author{
Mohammad Javad Aarabi ${ }^{1 *}$, Rahim Ebrahimi ${ }^{2}$
}

${ }^{1}$ Chaharmahal and Bakhtiari Science and Technology Park, Shahrekord, Iran

${ }^{2}$ Department of Mechanical Engineering of Biosystems, Faculty of Agriculture, Shahrekord University, Shahrekord, Iran

Received - May 25, 2017; Revision - August 29, 2017; Accepted - September 09, 2017

Available Online - September 10, 2017

DOI: http://dx.doi.org/10.18006/2017.5(4).573.577

\section{KEYWORDS}

Almond

Air velocity

Angle of mixture supply

Mixture feed rate

Separation error

Separation efficiency

\section{ABSTRACT}

The aim of the present study was to investigate the efficacy of pneumatic separation method in separation of almond kernels from its cracked shells. The influence of air velocity, mixture feed rates, distance between mixture inlet and kernels outlet, angle of mixture supply into tunnel and repeat times of operation on separation efficiency was also studied in this study. Results of study revealed that the separation efficiency decreased with increasing feed rate, angle of mixture supply into tunnel and distance between mixture inlet and kernels outlet. The highest $\eta \%$ was reported on $9.5 \mathrm{~m} / \mathrm{s}$ velocity while the lowest amount was reported on the $6.5 \mathrm{~m} / \mathrm{s}$. Increasing in repetition times have significant effect on the separation efficiency and it was reported higher with higher repetition time. Mixture of kernels outlet analysis revealed that separation of shells with $20-30 \mathrm{~mm}$ length give poor results and about $50 \%$ of the shells remained on kernels outlet.
* Corresponding author

E-mail: bioshk@yahoo.com (Mohammad Javad Aarabi)

Peer review under responsibility of Journal of Experimental Biology and Agricultural Sciences.

Production and Hosting by Horizon Publisher India [HPI] (http://www.horizonpublisherindia.in/).

All rights reserved.
All the article published by Journal of Experimental Biology and Agricultural Sciences is licensed under a Creative Commons Attribution-NonCommercial 4.0 International License Based on a work at www.jebas.org.

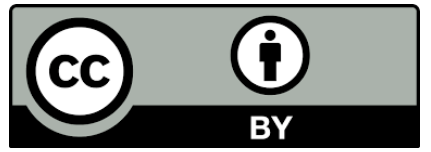




\section{Introduction}

Almond (Prunus amygdalus) is a native tree of Middle East, India and North Africa belongs to the family Rosaceae (Potter et al., 2007). Seeds of almond are widely used in desserts, candy and cooking. Its a good source of beauty, inspiration, food, medicines and anti-oxidant nutrients. Its kernel is an important source of energy (6 Kcal/g) and protein $(15.64 \%)$. Seed kernel has oil content ranged from $35.27 \%$ to $40 \%$ and it is an important source of oleic acid (Aydin, 2003). Almond seeds are not only used as dietary supplements but also has various pharmacological properties such as anti-stress (Bansal et al., 2009), anti-oxidant (Pinelo et al., 2004), immunostimulant (Puri et al., 2000), lipid lowering (Spiller et al., 1998), and laxative (Sharma \& Saamhita, 1981). Its versatile utility as a medicine and nutritional food increased the economic value of this fruit.

Harvesting and handling operations related to the almond are carried out manually. The most important process after almond cracking is the separating almond kernel from its cracked shell. This process usually carried out on hard floor with homemade threshing machine. Now in these days, for optimum threshing performance, processes of pneumatic conveying and storing was used by almond cultivars (Nwokolo \& Smartt, 1996).

According to Tado et al. (1999), for an agricultural engineer, along with the knowledge of agricultural engineering operations, accurate understanding of the basic properties experimental crop product such as grain separation processes, determination of the terminal velocity and the evaluation of the physical \& aerodynamic is also very necessary. Gorial \& O'Callaghan (1991) suggested that the separation of mixed components under an air stream is possible only when the accurate air pressure delivered and some of the components reach to their terminal velocity. Smith \& Stroshine (1985) reported that pneumatic separation of corn cobs from stalks is difficult, because the terminal velocities of some stalks overlapped with those of the cobs. Further, Uhl \& Lamp (1966) reported that approximately $94 \%$ wheat straw could be removed from the grain without grain loss under suitable terminal air velocity. Effect of moisture content on separation of rice grain with the help air velocity was also studied by Tado et al. (1999) and these researchers reported that the mean terminal velocity increased with the increase in moisture content. Yahaya (1999) investigated the aerodynamic properties of the small root crops viz. tiger nut (Cyperus esculentus), flowering bulbs (Gladiolus - Iridaceae gladius), onion sets (Allium cepa L.) and reported the required terminal velocities $8.4,22.0$ and $24.0 \mathrm{~m} \mathrm{~s}^{-1}$ respectively. El-Sayed et al. (2001) investigated the aerodynamic separation of the shelled peanut and found that the air separation of unshelled, split and intact seed components from the shells is difficult due to the interference of the terminal velocity of the components (El-Sayed et al., 2001).

The aim of present study was to record preliminary information on the dimensions and aerodynamic properties of the almond in order to develop a suitable separation device and using a pneumatic separator with the minimum of loss.

\section{Materials and Methods}

This experiment was carried out on some Mami cultivar almond, to predict the preliminary aerodynamic properties of these species at harvesting for a further post-harvesting process (shelling). This pneumatic isolator designed in Shahrekord University, Shahrekord, Iran to test the physical and mechanical properties. The intake system is divided into two parts, the upper part of the skin is prepared for the withdrawal and low for the output of the peanut (Figure 1).

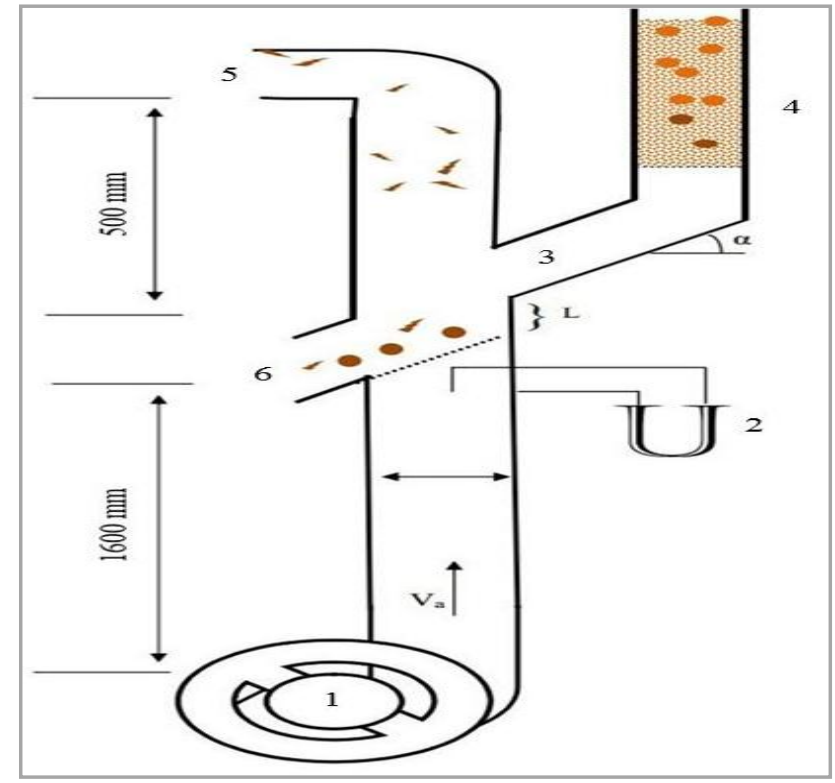

Figure 1 Test stand for the measurement of the terminal velocity of bulk materials (Design is developed by University of Shahrekord, Iran).
1- Air blower
2- Speedometer
3- Fall material tube
4- Storage tank
5- Shell outlet
6- kernel outlet
$\alpha$ - Entrance angle
L- Space between entrance of mixture and kernel outlet 
In order to evaluate the efficiency of pneumatic process of studied almond mixture separation, two indices were applied (i) separation efficiency $(\eta)$ that can also be used to assess the device efficiency

$$
\eta=\mathrm{b} 1 / \mathrm{b} 0.100
$$

whereas $\eta$ : separation efficiency; b1: total weight of contaminants in initial material possible to separate in pneumatic separator; b0: weight of contaminants separated from initial material in pneumatic separator

(ii) the separation precision coefficient $(\varepsilon)$ which characterizes the losses resulting from separating part of valuable grains along with the wastes:

$$
\varepsilon=\mathrm{e} 1 / \mathrm{e} 0.100
$$

$\varepsilon$ : separation precision coefficient; e1: total grain in initial material possible to separate in pneumatic separator; $\mathrm{e} 0$ : weight of grain separated from initial material in pneumatic separator;

The data were statistically analyzed by the ANOVA and Tukey tests for variance analyses and treatment means comparison respectively using the SPSS 24.0 (SPSS Inc, Chicago IL, USA) software.

\section{Results and Discussions}

In separation efficiency $(\eta \%)$ factor at the angle of $30^{\circ}, 45^{\circ}$ and $60^{\circ}$, highest efficiency was observed at $30^{\circ}$ and $45^{\circ}$ angle, but the difference between these groups are not significantly different ( $\mathrm{p}>$ 0.05). Similar trends were observed in case of separation precision coefficient $(\varepsilon \%)$ and maximum $\varepsilon \%$ was observed at the angle of $30^{\circ}$ and $45^{\circ}$. Here also, no significance difference was reported between these two groups but these two are significantly different $(\mathrm{p}<0.05)$ from the angle of $60^{\circ}$ (Table 1$)$.

Table1 Effect of various angles of $30^{\circ}, 45^{\circ}$ and $60^{\circ}$ on the

\begin{tabular}{|c|c|c|}
\hline$\underbrace{\text { Factor }}_{\text {Group }}$ & $\eta \%$ & $\varepsilon \%$ \\
\hline $30^{\circ}$ & $49.47 \pm 33.96$ & $6.33 \pm 9.26^{\mathrm{a}}$ \\
\hline $45^{\circ}$ & $48.13 \pm 34.68$ & $6.2 \pm 11.81^{\mathrm{a}}$ \\
\hline $60^{\circ}$ & $40.71 \pm 34.45$ & $3.16 \pm 7.41^{b}$ \\
\hline$P$ value & 0.08 & $0.01^{* *}$ \\
\hline
\end{tabular}
$\eta \%$ and $\varepsilon \%$ factors

Table 2 showed the effect of the separation unit diameter on the separation efficiency and separation precision coefficient. Result of study revealed increases in $\eta \%$ factor value with the reducing the diameters and the highest $\eta \%$ was reported at $12 \mathrm{~cm}$. A significant differences $(\mathrm{p}<0.05)$ was reported between all the tested diameters, but the difference between 36 and $60 \mathrm{~cm}$ was not statistically significant and the lowest $\eta \%$ value was observed at $60 \mathrm{~cm}$. Also the results of study indicated reducing trend in $\varepsilon \%$ factor. As separation efficiency, the highest value of separation precision coefficient was related to $12 \mathrm{~cm}$ and this difference was significantly different from the 36 and $60 \mathrm{~cm}$ groups ( $\mathrm{p}<0.05$ ).

Table 2 Effect of the 12, 36 and $60 \mathrm{~cm}$ diameter on $\eta \%$ and $\varepsilon \%$ factors

\begin{tabular}{|c|c|c|}
\hline grou (cm) & $\mathbf{\eta} \%$ & $\mathbf{\varepsilon} \%$ \\
\hline 12 & & \\
\hline 36 & $55.22 \pm 35.35^{\mathrm{a}}$ & $8.83 \pm 12.98^{\mathrm{a}}$ \\
60 & $45.06 \pm 34.51^{\mathrm{b}}$ & $4.29 \pm 7.83^{\mathrm{b}}$ \\
pvalue & $38.17 \pm 31.59^{\mathrm{b}}$ & $2.61 \pm 6.1^{\mathrm{b}}$ \\
\hline
\end{tabular}

**means within a column with different letter are significantly different $(\mathrm{p}<0.01)$.

In general, reduction was observed in $\eta \%$ factor with the increasing the feed rate (Table 3) and the highest and lowest amount was reported at 10 and $30 \mathrm{~g} / \mathrm{s}$ respectively, but this differences was not significantly different ( $p>0.05$ ) among the groups. In case of $\varepsilon \%$ factor highest and lowest feed rate were observed in 20 and $30 \mathrm{gr} / \mathrm{s}$ respectively, but the differences between groups was not significant ( $p>0.05)$.

Table 3 Effect of feeding rate (10, 20 and $30 \mathrm{gr} / \mathrm{s})$ on $\eta \%$ and $\varepsilon \%$

\begin{tabular}{|c|c|c|}
\multicolumn{3}{|c|}{ factors } \\
\hline Group (gr/s) & $\mathbf{\eta} \%$ & $\mathbf{\varepsilon} \%$ \\
\hline 10 & & \\
20 & $51.11 \pm 34.72$ & $4.99 \pm 8.96$ \\
30 & $45.32 \pm 34.66$ & $5.77 \pm 11.15$ \\
pvalue & $42.02 \pm 33.66$ & $4.97 \pm 9.11$ \\
& $0.09^{\text {ns }}$ & $0.75^{\text {ns }}$ \\
\hline
\end{tabular}

Ns: the different between means of groups was not significant. Generally, Table 4 showed an increase in $\eta \%$ factor during the air velocity. The highest $\eta \%$ was reported on $9.5 \mathrm{~m} / \mathrm{s}$ velocity while the lowest amount was reported on the $6.5 \mathrm{~m} / \mathrm{s}$. All groups showed a significant differences with the air velocity $(\mathrm{p}<0.01)$. 
Table 4 Effect of air velocity on the $\eta \%$ and $\varepsilon \%$ factors

\begin{tabular}{|c|c|c|}
\hline Froup $(\mathbf{m} / \mathbf{s})$ & $\mathbf{\eta} \%$ & $\mathbf{\varepsilon} \%$ \\
\hline 6.5 & & \\
\hline 7 & $3.81 \pm 3.98^{\mathrm{e}}$ & $0.00 \pm 0.00^{\mathrm{c}}$ \\
\hline 7.5 & $19.47 \pm 11.10^{\mathrm{d}}$ & $0.00 \pm 0.00^{\mathrm{c}}$ \\
\hline 8.5 & $40.30 \pm 12.23^{\mathrm{c}}$ & $0.00 \pm 0.00^{\mathrm{c}}$ \\
\hline 9.5 & $78.13 \pm 12.81^{\mathrm{b}}$ & $9.74 \pm 9.73^{\mathrm{b}}$ \\
\hline pvalue & $89.04 \pm 8.92^{\mathrm{a}}$ & $16.47 \pm 12.5^{\mathrm{a}}$ \\
\hline
\end{tabular}

**means within a column with different letter are significantly different $(\mathrm{p}<0.01)$.

The results also showed that increasing the number of repetitions in the air flow velocity also increases the efficiency of skin separation. However, the changes in skin separation efficiency are high with increasing repetitions, but this increasing is not different in different repetitions. Results are in agreement with the findings of Thomson et al. (1996), those who suggested 6 to 8 repetitions is good for separation hard skin. The increases in error and the separation efficiency due to the increase of airflow in the straw wheat product isolation was reported by Panasiewicz et al. (2008) and for corn crops by Faran \& McMillan (1979).

Many air separators are available but usually simpler and nonadjustable separators are most suitable in terms of capacity and maintenance (Boling, 1979). One of the simplest pneumatic hull separators has a vertical cylindrical column in which previously cracked almond are fed downwardly through a rising stream of air (Reshadsedghi \& Mahmoudi, 2013). A typical problem found in industry is the fact that as hull and meat particles are progressively cracked in smaller sizes, their terminal velocities become closer, precluding efficient separation (Boling, 1979).

Increasing the separation efficiency by decreasing the mixing angle was also reported by Faran \& Mc Millian (1979) for corn crops. The cause of increased skin secretion efficiency by reducing the angle of entry is due to reducing the angle of entry reduces the movement rate of the mixed components across the tunnel. This cause reduces material density versus airflow and also increases the airflow effect on mixed components and, of course, cause increases the efficiency of skin separation.

\section{Conclusion}

In this study, an effective and low-cost system was applied to pneumatic isolation of almond flakes from woody skin under the influence device velocity changes, mixed feed rate and space between entrance of mixture and kernel outlet. With increasing air velocity, the skin isolation increased but increasing the air velocity of more than 9.5 meters per second, an error observed in separation operations. With the increasing number of operations repeat, skin isolation efficiency takes an increasing rate.

\section{Conflict of interest}

The authors declare no conflict of interest.

\section{References}

Aydin C (2003) Physical properties of almond nut and kernel. Journal of Food Engineering 60: 315-320.

Bansal P, Sannd R, Srikanth N, Lavekar GS (2009) Effect of a traditionally designed nutraceutical on the stress induced immunoglobulin changes at Antarctica. African Journal of Biochemistry Research 3: 1084-1088.

Boling F (1979) Principles of hull removal from oilseed. Oil Mill Gazetteer 2: 29-31.

El-Sayed AS, Yahaya R, Wacker P, Kutzbach HD (2001) Characteristic attributes of the peanut (Arachis hypogaea L.) for its separation. International Agrophysics $15: 225-230$.

Farran TG, Macmillan RH (1979) Grain-chaff separation in a vertical air stream. Journal of Agricultural Engineering Research 24: $115-121$.

Gorial BY, O'Callaghan JR (1991) Separation of grain from straw in a horizontal air stream. Journal of Agricultural Engineering Research 49: 273-284.

Nwokolo E, Smartt J (1996) Peanut (Arachis hypogaea L.). In: Food and feed from legumes and Oilseeds. Chapman and Hall: 1st edition, London; New York 48-58.

Panasiewicz M, Zawslak K, Kusinska E, Sobczak P (2008) Purification and separation of loose materials in a pneumatic system with vertical air stream. Teka Kom Mot Energ Roln 8: 171-176.

Pinelo M, Rubilar M, Sineiro J, Nunez MJ (2004) Extraction of anti-oxidant phenolics from almond hulls (Prunus amygdlaus) and pine sawdust (Pinus pinaster). Food Chemistry 85: 267-273.

Potter D, Eriksson T, Evans RC, Oh S, Smedmark JEE, Morgan DR, Kerr M (2007) Phylogeny and classifcation of Rosaceae. Plant Systematics and Evolution 266: 5-43.

Puri A, Sahai R, Singh KL, Saxena RP, Tan don JS, Saxena KC (2000) Immunostimulant activity of dry fruits and plant materials 
which are used in the Indian traditional medical system for mothers after child birth and invalids. Journal of Ethnopharmacology 71: 89-92.

Reshadsedghi A, Mahmoudi A (2013) Detection of almond varieties using impact acoustics and artificial neural networks. International Journal of Agriculture and Crop Sciences 5: 10081017.

Sharma RP, Saamhita C (1981) Agnivesha Treatise. Sutrashana. Varanasi: Chokambha Sanskrit Sansthan.

Smith RD, Stroshine RL (1985) Aerodynamic separation of cobs from corn harvesting residues. Transactions of the ASAE 28: 893-902.

Spiller GA, Jenikins DA, Bosello O, Gates JE, Cragen LN (1998) Bruce nuts and plasma lipids: An almond-based diet lowers the
LDL-C while it preserves the HDL-C. Journal of the American College of Nutrition 17: 285-290.

Tado CJM, Wacker P, Kutzbach HD, Suministrado DC (1999) Aerodynamic properties of paddy. Agricultural Engineering Journal 8: 91-100.

Thompson JF, Rumsey TR, Connell JH (1996) Drying hulling and shelling. In: Micke WC (Ed.) Almond production manual. University of California, Agriculture and Natural Resource, Oakland CA, USA.

Uhl JB, Lamp BJ (1996) Pneumatic separation of grain and straw mixtures. Transactions of the ASAE $9: 244-246$.

Yahaya R (1999) Increasing effectiveness of mechanical harvesting of small root crops and bulbs by removing a layer surface. Ph.D. Thesis submitted to the Belarusian State Agrarian Technical University, Minsk, Belarus. 